\title{
ESCLAVITUD, DOMINIO Y LIBERTAD HUMANA SEGÚN DOMINGO DE SOTO
}

\author{
Jörg Alejandro Tellkamp \\ Universidad Nacional de Colombia
}

\section{RESUMEN}

En este artículo se analizará la teoría del dominio de Domingo de Soto y su relación con los conceptos de libertad y esclavitud. El concepto de dominio indica que este autor ha alcanzado una noción de derechos subjetivos. Sin embargo, las implicaciones de este concepto en el ámbito de la Filosofía Política, sobre todo en relación con el concepto de la esclavitud, tanto natural como legal, llevan a la conclusión de que Soto con su noción de derechos subjetivos, no tuvo en mente una idea moderna de derechos individuales.

Palabras clave: Domingo de Soto, libertad, esclavitud, dominio, derechos subjetivos.

\begin{abstract}
This article attempts to analyze Domingo de Soto's theory of dominion and its relationship with the concepts of liberty and slavery. The concept of dominion shows that this author did in fact have a notion of subjective rights, however, its implications in the field of his political philosophy, mainly in relation with the concept of natural and legal slavery, leads to the conclusion that he did not reach the modern idea of individual rights.
\end{abstract}

Key words: Domingo de Soto, liberty, slavery, dominion, subjective rights.

\section{INTRODUCCIÓN}

Decir que la Escuela de Salamanca sostiene una idea prototípica de los derechos subjetivos y de los derechos humanos no constituye una afirmación particularmente novedosa. ${ }^{i}$ En el presente escrito, cuyo propósito consiste en indagar un aspecto del pensamiento político del dominico Domingo de Soto (1495-1560), no se pretenderá cuestionar que la Escuela de Salamanca en general y Soto en particular hayan formulado un concepto de derechos subjetivos, es decir una noción según la cual existe un derecho que una persona puede exigir con miras a una acción o una cosa. Tampoco se cuestionará que esta idea haya conducido históricamente a la formulación de derechos humanos, por lo menos en el sentido cómo los entendemos hoy en dia, es decir como derechos inalienables, por ejemplo el derecho a la vida y a la integridad física, el derecho a la libre expresión, a la protección contra la arbitrariedad estatal, etc. 
Pero sí se pondrá en duda que esta caracterización de los derechos subjetivos haya llevado a Soto a una formulación de los derechos humanos, por lo menos tal como los entendemos actualmente. Así, la discusión de Soto acerca de la esclavitud, como una forma de dominio, y la relación de éste con el concepto de libertad apoya la idea de los derechos subjetivos y, sin embargo, éstos no conducen a derechos como los mencionados arriba. Si mi lectura de Soto es correcta, se podría pensar que el dueño de un esclavo tiene derechos subjetivos exigibles respecto del dominio un esclavo, mientras que éste no posee el mismo derecho subjetivo respecto de la preservación de su libertad. Esto, claro está, sería completamente contrario a la noción de derechos humanos.

En lo que sigue se establecerá de manera somera el significado del término «libertad», y después se intentará mostrar que en Soto ya encontramos una formulación rudimentaria de los derechos subjetivos, lo cual se puede mostrar analizando el concepto de dominium. No obstante esta caracterización de los derechos subjetivos, no existió una formulación de los derechos individuales, inalienables y exigibles por cualquier persona. Con el propósito de corroborar este punto, se procederá a analizar el concepto de esclavitud y las diferentes estrategias para legitimar esta práctica, como por ejemplo la captura de prisioneros en el transcurso de una guerra justa. Finalmente se retomará el concepto de dominium, que para Soto es un concepto analógico. Esto dificulta, a mi manera de ver, una interpretación de Soto como defensor de derechos individuales.

\section{UNA CORTA DEFINICIÓN DE LIBERTAD}

Por razones de espacio no se podrá dar una definición exhaustiva de «libertad», por lo que se limitará a resaltar dos aspectos principales que permiten asir ese concepto. Por un lado se concibe libertad como aquello que se opone a una noción de determinismo. Este sentido trata primordialmente del hecho ontológico de que el hombre, independientemente de su estatus actual, haya sido creado como libre por el hecho de ser una imagen de Dios. Por el otro lado, y estrechamente relacionado con la primera noción, se concibe «libertad» como una forma de hablar del libre albedrío, es decir de una facultad del alma que puede querer o escoger libremente $x$ o $y$ o sencillamente no querer ni $x$ ni $y$.

Ambos aspectos se encuentran en el pensamiento de Domingo de Soto, o sea que el ser humano es ab initio libre en ambos sentidos. De nuevo, esto quiere decir que el acto de creación divino hizo al hombre a imagen y semejanza suya y esto, a su vez, significa que el ser humano participa de manera significativa, pero imperfecta de los atributos esenciales de Dios. Éstos abarcan sobre todo la racionalidad y la libertad divinas, lo que significa que el ser humano es, de manera participativa, racional y que por ende, como ser racional, no está sometido a la necesidad de causas y efectos naturales; por esta razón puede ser dueño de sus propios actos ejerciendo el liberum arbitrium.

Desde el punto vista bíblico hay que añadir que el libre albedrío sufre una limitación considerable al producirse el pecado original. La caída del paraíso produce la división de los bienes y en general establece la legislación humana. En consecuencia de eso, la libertad de ciertas personas puede ser limitada por el derecho positivo de gentes.

\section{DOMINIUMY ESCLAVITUD}

Las obras de Domingo de Soto que de manera destacada se ocupan del problema de esclavitud y libertad son su relección De dominio, leída en Salamanca el año 1534, y su gran obra De iure et iustitia, publicada por primera vez el año 1556. En primera instancia expondré las bases conceptuales de la relección, porque ya en ese texto tempranero se encuentra una dilu- 
cidación terminológica exacta de los conceptos de dominio (dominium) y derecho (ius), que son claves para la comprensión del estatus legal y moral de la esclavitud y, por ende, de la libertad humana. Entre la variedad de temas que Soto analiza al respecto, cabe destacar tres preguntas: (1) qué es el dominio; (2) quién califica como dueño de un dominio y (3) cómo se caracteriza la esclavitud como una especie de dominio.

\section{i) Definiciones de dominio}

El primer tema, que trata de la naturaleza del dominio, tiene como punto de partida la reflexión de Soto el texto del Génesis I, 28: «Someted la tierra y dominad sobre los peces del mar y sobre las aves del cielo [...]». ${ }^{2}$ Soto precisa este texto bíblico, porque establece que la constitución de cualquier dominio requiere de la racionalidad; así, sólo los seres humanos se convierten en auténticos sujetos para el ejercicio de dominios. ${ }^{3}$ De esta manera, la racionalidad se convierte en un requisito necesario para ejercer un dominio.

El teólogo salmantino continua explicando que en el lenguaje de los teólogos y los juristas el dominio equivale a una potestad (potestas) o un derecho (ius) que una persona tiene respecto de una cosa (p. 102sqq.) ${ }^{4} \mathrm{El}$ concepto del dominio representa de esta manera una relación asimétrica y jerárquica entre un ser racional y un ser ontológicamente inferior. Evidentemente, para comprender adecuadamente esta relación, es necesario definir de manera exhaustiva el concepto de dominio. Para ello se dejan identificar en la obra de Soto cuatro definiciones de dominio, que al parecer se tienen que entender como complementarias.

(1) En una primera tentativa para definirlo dice lo siguiente: «El dominio es la potestad o facultad próxima para apropiarse de algunas cosas para su uso lícito según las leyes y los derechos razonablemente instituidos». ${ }^{5}$ Sin embargo, Conrado Summenhart ${ }^{6}$, quien sigue a Juan Gerson $^{7}$, opina que la potestad sobre un objeto equivale estrictamente a un derecho sobre el mismo. Ante esto objeta Soto que dominio (dominium) y derecho (ius) no pueden ser equivalentes, justamente porque un dominio siempre incluye la superioridad de alguien respecto de una cosa. De esta manera se puede decir que el hijo posee ciertos derechos respecto de su padre, pero esto no significa que éste tenga una potestad sobre su padre ${ }^{8}$ La relación entre derecho y dominio es sin duda muy estrecha, pero no se trata de términos idénticos.

(2) Una segunda definición de dominio es la siguiente: «Por consiguiente, basta con que al definir el dominio digamos que es la potestad o la facultad de apropiarse de alguna cosa para nuestro uso» ${ }^{9}$ Esta definición, no obstante, genera una inquietud, porque parece borrar la diferencia tácita entre dominio y uso (usus) o usufructo (usufructus). Si se identificara el dominio con el uso o usufructo, entonces cualquier persona que posee ese derecho, podría apropiarse de ella. ${ }^{10}$

2 Soto, D., Relecciones y opúsculos: Introducción general, De Dominio, Sumario, Fragmento An liceat, vol. 1, Brufau Prats, Jaime (ed.), Salamanca, Editorial San Esteban, 1995, p. 100, 31 sqq.

$3 \quad$ Ibid., p. 102, 41-43.

4 Ibid., p. 102, 9 sq.: «At vero theologi e iurisconsulti aliter usurpant hoc nomen, nempe pro potestate seu iure quis habet in aliquam rem».

$5 \quad$ Ibid., p. 104, 2-4: «Dominium est potestas vel facultas propinqua assumendi res aliquas in sui usum licitum secundum leges et iura rationabiliter institutas». La traducción es de la edición de Brufau Prats.

6 Summenhart, C., De contractibus, Hagenau 1550 f. 1: «[...] Quicunque habet ius in aliqua re, potest dici dominus illius rei: igitur illud ius poterit dici dominiums. Citado en Tierney, B., The Idea of Natural Rights: Studies on Natural Rights, Natural Law, and Church Law 1150-1625, Grand Rapids/Cambridge, Eerdmans, 1997, p. 244 nota 19.

7 Gerson, J., De postestate ecclesiastica et de origine iuris et legum consideratio, en Opera Omnia, vol. 2, Antverpiae, Sumptibus Societatis, 1706, col. 252-253.

8 Soto, D., o.c. p. 106, 15 sqq.

9 Ibid., p. 106, 38 sq.: «Igitur satis est si definientes dicamus quod est potestas seu facultas assumendi rem aliquam in usum nostrum [...]».

10 Ibid., p. 108, 17-19: «[...] Sed usufructuarius habet ius quidem utendi fructibus, et potest transferre hoc ius utendi in alium, non tamen potest vendere vel donare hortos $[\ldots]$ \%. 
(3) Con el fin de precisar este asunto, parece ser necesario introducir una tercera definición: «[...] El dominio es potestad o derecho propio de tomar la cosa para cualquier uso que no esté prohibido por la ley.» ${ }^{11}$ Es notable que Soto caracterice el dominio en términos de un derecho de uso que no deba contradecir la ley. ${ }^{12}$ Esta correlación del derecho con la ley implica que el ladrón no se convierte en el dueño del bien robado, porque el robo es de suyo legalmente reprehensible. ${ }^{13}$ En este sentido, el derecho se convierte, en palabras de A. Brett, en un 'poder subjetivo lícito' ${ }^{14}$ cuyo contenido se dirige hacia la sustancia de cosa (substantia rei) y no a los atributos accidentales del mismo. ${ }^{15}$

(4) Tanto en el De dominio como en el De iure et iustitia da Soto una cuarta definición que complementa y justifica la tercera mencionada. En ella, Soto no enfatiza tanto la legalidad del derecho de uso, sino el hecho de que todo el dominio es una consecuencia del ejercicio del libre albedrío. ${ }^{16}$

\section{ii) El sujeto del dominio}

Correspondientemente, respecto de la pregunta acerca del sujeto propio del dominio, aclara Soto que un dueño solamente se puede considerar como tal, cuando tiene el libre albedrío para libremente disponer de sus dominia ${ }^{17}$ Esta característica no se encuentra en los animales, a diferencia de lo que afirmaba Juan Gerson, quien pensó que el cualquier dominio pertenece al ámbito de la gracia y que, por tanto, se extiende asimismo hacia los seres irracionales. Según Soto, el dominio de las cosas es natural y no divino; de esta manera el dominio natural surge de la naturaleza de un estado de cosas, de manera que la posesión de un cuerpo exige naturalmente otros tipos de posesión como lo son el alimento, vestimenta, etc. ${ }^{18}$ Ahora bien, dado que Soto excluye el dominium divinum como una forma relevante de posesión, es decir que esto sea mío y aquello tuyo, es para él necesario excluir a los seres no racionales como sujetos de un dominio verdadero. Si bien el burro puede usar la paja que come, no ejerce por ello un dominio sobre ella. Esto quiere decir que solamente aquellos seres califican como dueños de una cosa, si son capaces de explícita o implícitamente expresar su interés por ella. En este sentido es importante anotar que este razonamiento permitió que Soto defendiera el dominio legítimo de los indígenas americanos, siendo ellos seres esencialmente racionales y capaces de realizar acciones voluntarias y son, por tanto, sujetos idóneos para ejercer un dominium humanum. ${ }^{19}$ Cabe anotar que es sobre todo en este sentido del dominio como una facultad o un derecho respecto de una cosa el que usualmente se relaciona con el desarrollo de los derechos subjetivos.

11 Ibid., p. 110, 18-20: «[...] Dominium est potestas seu ius proprium assumendi rem ad quemcumque usum qui non est prohibitum lege».

12 Brett, A., Liberty, Right and Nature: Individual Rights in Later Scholastic Thought, Cambridge, Cambridge University Press, 1997, p. 141: «In general terms, Soto's priority in treating right and dominium appears to be the desirability of integrating nature firmly into the sphere of the juridical».

13 Véase el libro IV, q. 1 a. 1 de Soto, D., De iustitia, et iure, libri decem. Salmanticae, Andrés de Portonaris, 1556, reimpresión con traducción de González Ordóñez, Marcelino, vol 2., Madrid, Instituto de Estudios Políticos, 196, p. 288-291. cf. también Brett, A., o.c. p. 150.

14 Cf. Brett, A., o.c.: «Right is used [...] in the sense of 'licit subjective power' [...]».

15 Soto, D., o.c. p. 281a.

16 Soto, D., o.c. p. 279 a sq.: «Dominium autem non quodcunque ius et potestatem significat, sed certè illam quae est in rem qua vti pro libito nostro possumus in nostram propriam vtilitatem, quamque ob nosipsos diligimur». Véase también Soto, D., De dominio p.124sqq.

17 Ibid.

18 lbid. p. 128,8 sq.

19 Ibid. p. 136. 


\section{iii) La esclavitud como forma de dominio}

La esclavitud es una forma específica de dominio que aparentemente contrasta con la afirmación acerca de la libertad constitutiva del ser humano. Esta libertad constituye un hecho del derecho natural, es decir que todos los seres humanos son ab initio libres y poseedores de un libre albedrío, lo que significa que tal libertad no puede ser anulada o eliminada. ${ }^{20}$ No obstante esta afirmación fuerte acerca de la libertad humana, existe al parecer la necesidad de conciliarla con la institución de la esclavitud, cuyo núcleo esencial niega el libre desempeño del ser humano. ${ }^{21}$

Ya las Institutiones de Justiniano establecen un marco conceptual dentro del cual la esclavitud contradice la naturaleza humana (esclavitud natural) siendo, sin embargo, justificable como parte del derecho de gentes (esclavitud legal). ${ }^{22}$ Aunque las Institutiones niegan la existencia de una esclavitud por naturaleza, piensa Soto, siguiendo a Aristóteles, que este concepto sí tiene cabida en el contexto de los dominios humanos. Pero a diferencia del Estagirita, Soto desarrolla en la cuestión 1 artículo 1 del cuarto libro de su De iure et iustitia un concepto de esclavitud natural que pretende reconciliar la libertad humana con la sumisión de una persona bajo otra.

La pregunta más importante es si un ser humano puede ser sèñor (dominus) de otro, pregunta que conduce a la distinción tradicional entre la esclavitud natural y legal. ${ }^{23}$ Aquí es de interés la caracterización de Soto de la esclavitud natural: «La [servidumbre] natural es aquella que ejercen los hombres de ingenio más despierto sobre los que lo tienen más torpe y rudo». ${ }^{24}$ Esta afirmación parece contradecir el supuesto de una igualdad esencial de todos los seres humanos y asimismo parece acercarse notablemente a la postura de Juan Ginés de Sepúlveda. Sin embargo, la semejanza con el cordobés es tan sólo aparente.

El punto de partida para las reflexiones de Soto sobre la esclavitud natural constituye la convicción de que entre los seres humanos no existen diferencias naturales de facto que permitan establecer una dominatio naturalis. Pero si todos los seres humanos son esencialmente iguales, ¿cómo justifica la esclavitud natural? A diferencia de Sepúlveda, piensa Soto que un dominio natural se justifica debido a las diferencias contingentes, por ejemplo, porque los indígenas americanos poseen un nivel cultural inferior al de los españoles. No se trataría de una diferencia esencial en el sentido en que, por ejemplo, todos los indígenas son esencialmente inferiores. La tesis acerca de la inferioridad cultural es, desde luego, problemática, porque depende de una determinada cosmovisión cultural, y sin embargo permite a Soto invertir los parámetros tradicionales para la justificación de la esclavitud natural. Según Soto, el concepto de esclavitud natural establece que el beneficiario de la relación entre señor y esclavo no es el señor, sino el esclavo, sobre todo con miras a superar el estado de inferioridad cultural en que se encuentra. ${ }^{25}$ Esta inferioridad a su vez se debe a que un individuo (o un grupo de individuos) no tiene la posibilidad de vivir secundum rationem. En este caso, la obligación de velar por el

20 Soto, D., o.c. IV, q. 2 a. 2 p. 288 b: «Nullum ius potest naturali derogare: naturali autem omnes homines nascuntur liberi $[\ldots]$ »..

21 Soto, D., o.c. p. 288b: «[...] Servitus [est] qua quis dominio alieno contra naturam subijcitur». Véase $i b i d$. II, q. 1 a. 3 p. 198b: «[...] Philosophus quando ait homines esse iure naturae seruos, non accipit ius nature simpliciter: nam absolutè humana natura pensata, non est cur magis vnus seruiat quam alter [...]».

22 Justiniano, Institutionum, sive elementorum D. Justiniani sacratissima principis libri IIII ad editionem Gregorii Haloandri, Lugduni, Apud Guilelmum Rovilium, 1548, p. 15 titulus III: «Servitus autem est constitutio iuris gentium, qua quis dominio alieno contra naturam subijcitur».

23 Soto, D., o.c. p. 288 b sqq.

24 Soto, D., o.c. p. 288 b: «Naturalis [servitus-J.A.T.] est qua homines elegantiores ingenij reliquis hebetibus ac rudibus dominant».

25 Cf. Brufau Prats, J., El pensamiento politico de Domingo de Soto y su concepción de poder, Salamanca, Universidad de Salamanca, 1960, pp. 121-140. 
bienestar de otra persona se transmite a la persona que sí está en condiciones de vivir racionalmente. No es del todo claro si se trata de una variación del principio cristiano del amor del prójimo, pero sí es claro que la función pedagógica de la esclavitud natural elimina cualquier función económica y militar que ésta pueda tener. ${ }^{26}$ Llevando esta reflexión a la situación de los indigenas americanos, salta a la vista que éstos, en la óptica de Soto, tienen son esclavos naturales en el sentido mencionado, pero tan sólo hasta llegar al punto en que puedan ejercer adecuadamente sus funciones racionales. Por eso, esta esclavitud no es permanente, ya que el estado de ignorancia puede ser superado y, por ende, las razones para la esclavización. Esta posibilidad de ingresar a un estado cultural superior también significa que el misionero tiene la obligación de acercar a los indígenas a un estado cultural y religioso superior.

Una dificultad superficial con este tipo de esclavitud reside en la pregunta sobre la clase de derecho a que pertenece, es decir si pertenece al derecho natural o al ius gentium. ${ }^{27}$ La primera alternativa, o sea que la esclavitud natural forme parte del derecho natural, no es aceptable, porque se generaría una contradicción con la libertad humana, garantizada justamente por el derecho natural. Pero la segunda alternativa también genera dificultades, porque tiene que recurrir a diversas estrategias problemáticas para justificar la esclavitud natural como parte de la legislación humana, como lo es, por ejemplo, la guerra justa. Pero, si la guerra justa se considerara como justificación suficiente, entonces se estaría aplicando una justificación tradicional de la esclavitud legal al ámbito de la esclavitud natural.

Con todo, la justificación de la esclavitud natural no se debe al derecho natural, sino a un estado de cosas que, junto con una serie de normas y preceptos, como por ejemplo ayudar al prójimo, convierten este tipo de esclavitud en una institución de culturización. Esto no tiene mucho en común con el concepto de la esclavitud como una forma de dominio y como pérdida de libertad. Por eso aclara Soto que se trata de una forma impropia de servitus naturalis. Esto quiere decir que él reinterpreta la noción aristotélica de esclavitud natural hasta el punto de no solamente invertir la relación señor-esclavo, sino también hasta preservar el núcleo de la libertad humana.

A diferencia de la esclavitud natural, pertenece la esclavitud legal estrictamente al ámbito del derecho positivo de gentes; se justifica por medio de interacciones sociales que a su vez son la consecuencia del pecado original, como lo son la guerra justa y la autoventa. De esta manera, el cautiverio de prisioneros en el transcurso de una guerra justa permite justificar la toma de esclavos. Sea como sea, cualquier justificación de la esclavitud legal tiene que dar cuenta con el hecho de que ella niega de manera permanente el libre desempeño de las personas esclavizadas. ${ }^{28}$ Por esa razón es tanto más importante analizar esas justificaciones.

También la autoventa legitima, según Soto, la esclavitud, asunto que podría justificarse por la extrema necesidad en que se encuentra una persona. Desde luego habría que preguntarse si en este caso la vida propia tiene un mayor valor que la libertad. Soto concede que la vida tiene efectivamente un valor superior al de la libertad, porque solamente se podría razonablemente hablar de la libertad de una persona, si ésta se encuentra con vida. ${ }^{29}$ Por eso es preferible estar con vida que ser libre. ${ }^{30}$ No obstante la plausibilidad de esta afirmación, parece que para Soto

26 Soto, D., o.c. p. 290 a.

27 Soto, D., o.c. p. $291 \mathrm{a}$ : «Existit enim servitus iure gentium». En este caso es importante recalcar que para Soto el derecho de gentes pertenece al derecho positivo humano y no al derecho natural; véase Brett, S., The Justification of Slavery: A Comparative Study of the Use of the Concepts of ius and dominium by Thomas Aquinas, Francisco de Vitoria and Domingo de Soto in Relationship to Slavery, Ann Arbor 1987, p. 184.

28 Soto, D., o.c. p. 290b: «[...] Qui servus vocatus est, servus [manet]».

29 Soto, D., o.c. p. 289a: «Nam etsi homines facti sunt à deo liberi: tamen tam innatum est animantibus cunctisdesideriumac ius servandi vitam, ut possint se eius gratia miseri in servitutem adigere. Nam licèt [n]on bene pro toto libertas venditur auro: vendi tamen pro vita fas est, quae omni est pretiosior auro".

30 Soto, D., o.c. p. 289 b: «Si enim quis gratia sustinendae vitae libertate se privare potest, satius quisque ducere debet servitute quam morti tradi». 
el concepto de libertad difiere notablemente del concepto moderno donde la libertad se vislumbra como un valor superior a cualquier otro, incluso a la vida.

En el estado de esclavitud legal, el esclavo pierde cualquier derecho y tiene la función de beneficiar a su dueño. ${ }^{31}$ Este tipo de esclavitud es, a diferencia de la natural; una institución social creada por el ser humano, tendiendo como condición inicial el pecado original que permitió que se originase la división de las cosas y, por ende, el:dominio. Ahora bien, la esclavitud legal como institución humana es regulada por otra institución humana: el derecho de gentes. El contexto del derecho de gentes hace necesario analizar otra importante estrategia de justificación de la esclavitud, es decir la guerra justa, la cual tradicionalmente se ha visto como una razón suficiente para tomar esclavos legal y legítimamente.

Los lineamientos básicos de Soto siguen los parámetros establecidos por Francisco de Vitoria. ${ }^{32}$ Como éste, Soto remite al Comentario a las Sentencias del dominico español Pedro de Palude (1275-1342), quien dice que todo bien tomado en el transcurso de una guerra justa pertenece al que la gana, lo que atañe de igual manera a bienes inmuebles y muebles, como los prisioneros de guerra. ${ }^{33}$ Claro está que esta afirmación es bastante general, porque equipara cosas y seres humanos. Por esta razón y otras, esta estrategia de justificación ya fue criticada por Bartolomé de Albornoz, quien agudamente constata «[...] que se yo si el Esclavo que compro fue justamente captivado [...]», es decir que, aún asumiendo que el principio legal tuviese validez, no existe la posibilidad empírica de saber si la situación concreta del cautiverio correspondía a la de una guerra justa. ${ }^{34}$ Además no se desprende de la posesión de bienes que las personas capturadas sean cosas que puedan cambiar de «dueño». ${ }^{35}$ En suma no parecen existir los argumentos suficientes para justificar la esclavitud como consecuencia de una guerra justa. $^{36}$

Si bien los textos de Soto no arrojan una imagen clara y convincente de por qué la captura en el transcurso de una guerra justa sea una justificación plena de la esclavitud, se puede, sin embargo, pensar en al menos una razón implícita que hace que la postura de Soto sea más plausible: la esclavitud preserva la vida de quien es capturado en una guerra justa, en oposición a aquellos que son capturados en una guerra injusta y quienes pueden sufrir cualquier tipo de vejámenes. El vencedor de una guerra justa no podría disponer libremente de la vida del capturado, porque se aplicaría el principio de que sólo Dios dispone verdaderamente sobre la vida de los seres humanos. Como se verá, el dueño no sería propiamente el dueño de la vida del esclavo, sino que tan solo tendría un derecho de uso sobre él. Esta razón, que se deriva de la premisa que la vida vale más que la libertad, se basa, como se había mencionado antes, en el pecado original arraigado en la naturaleza de todos los seres humanos. En este sentido, la esclavitud legal constituye, como dice Soto, una esclavitud natural per accidens, cuyo propósito consiste en castigar esa afrenta inicial. ${ }^{37}$

31 Soto, D., De iure IV, q. 2 a. 2 p. 289 b.

32 Cf. Soto, De dominio p. 150. Véase también Vitoria, F., Relectio de iure belli o paz dinámica, Escuela española de la paz, Primera generación 1526-1560, Pereña, L. et al. (eds.), Madrid, C.S.I.C, 1981.

33 Palude, P., Scriptum in librum quartum sententiarum, Venetiis, Bonetus Locatellus, 1493, d. 15 q. 3 a. 3 concl.p. 69r: «Prima [conclusio] an sit facienda de illicite acquisitis [...]. Dico autem rapinam iniustam: quia in acquisitis in bello iusto transfertur dominium et liberum captus sit seruus. Non puto autem homines de christianis ab alijs christianis in bello etiam justo captis [...]»).

34 Véase Albornoz, B., Arte de los contractos, Valencia, Pedro Huete, 1573 f. 130vb.

35 Ibid. f. 130vb.

36 Al contrario, la argumentación parecería sugerir que las personas capturadas no pueden ser esclavizadas; cf. Soto, D., De iure IV, q. 2 a. 2 p. 290 a.

37 Soto, De dominio p. 150, 41-44: «Unde servitus non est primo modo naturales quia natura intendit libertatem, sed est de per accidens naturales, id est ratione peccati est data in poena. Unde in bello poena hostis est quod sit servus». 


\section{DOMINIUM COMO CONCEPTO ANALÓGICO}

Se ha visto que la concepción de la esclavitud como una forma de dominio es problemática. Este carácter problemático se corrobora si se toma en cuenta el supuesto de que dominium es un concepto analógico, es decir que el dominio humano se predica de una manera derivada e impropia respecto del dominio que Dios ejerce sobre la creación. Soto trata de explicar cómo la libertad dada por Dios es compatible con una filosofía política de corte aristotélico, o sea cómo una antropología cristiana puede coincidir con la esclavitud como institución legal. En forma de punto de partida afirma' Soto:

[...] Creo que entre las criaturas solamente el hombre es señor de las cosas. Pero, de una manera Dios es señor y de otra manera la criatura; porque Dios es absolutamente señor puesto que puede usar de la criatura de cualquier manera $[\ldots]{ }^{38}$

En este contexto Soto también pregunta si el ser humano es dominus de su propia vida, es decir si puede ejercer una potestad plena sobre su vida y sus miembros, ante lo cual afirma taxativamente que ${ }^{39}$ :

(1) El ser humano no es dueño de su vida, es decir que nadie puede libremente disponer sobre su propia vida, por ejemplo, cometiendo suicidio, lo cual es prohibido por «la ley de la justicia». ${ }^{40}$ Siempre cuando se habla de un dominio, se implica que éste se basa en relaciones jerárquicas. Como el ser humano no es superior a sí mismo, tiene que ser Dios el que sea propiamente dueño de la vida humana.

(2) No solamente un ser humano no tiene un dominio sobre su vida y sus miembros, sino que ningún otro ser humano lo tiene, porque en este caso tampoco se podría hablar de una jerarquización relevante, como la que existe entre Dios y la creación, la cual es ontológicamente inferior a él.

(3) Soto concluye que solamente Dios puede ser propiamente el dueño de la vida humana y de todas las partes que la componen. ${ }^{41}$

Si ningún ser humano puede ser propiamente dueño sobre sí mismo ni sobre otros, entonces, ¿por qué insiste Soto en legitimar la esclavitud? ¿No parece existir una contradicción entre sus supuestos ontológicos y su convicción acerca de la esclavitud legal? Si un ser humano no es propiamente dueño de sí mismo y si otro ser humano tampoco puede propiamente ser dueño de otro, entonces la esclavitud como una forma de dominio sobre otro no debería existir. Sin embargo, Soto acepta que el derecho de gentes legitima, al menos legalmente, una sumisión efectiva de un ser humano bajo otro. Existe, no obstante, la posibilidad de ver la esclavitud como un dominio, no sobre la vida del esclavo, sino como un derecho para usarlo con miras a determinados fines sin que esto conduzca a una disposición sobre su vida. Pero, de nuevo sería difícil ver cómo una concepción de este tipo pueda ser compatible con una esclavitud legal ejercida con miras al beneficio de un dueño y que a todas luces va en detrimento del esclavo.

38 Soto, De dominio p. 134, 1-4: «[...] Credo quod inter creaturas solus homo est dominus rerum. Sed aliter Deus est dominus, aliter creatura; nam Deus est absolute dominus, nam potest uti creatura quomodocumque [...]).

39 Soto, De iure IV q. 2 a. 3 p. 291a-295a: «Utrum homo sit vitae suae ac famae dominus».

40 Soto, o.c. p. 291 b: «[...] Homo autem se occidere non potest, lege iustitiae id vetante [...]».

41 Soto, o.c. p. 292b: «Deus est absolutus vitae dominus, nempe qui non solum tanquam judex puniendo, videlicet tamquam custos defendendo: sed absolute tanquam humanae vitae autor potest homines morti tradere, sicut unusquilibet iumentum suum». 


\section{CONCLUSIÓN}

Si bien es posible ver en Soto un precursor de uná formulación prototípica de los derechos subjetivos, siendo estos una facultad o potestad con miras a algo, no se desprende de ello que él haya abogado por una concepción «liberal» de tales derechos como derechos individuales que pueden ser exigidos por todos los seres humanos por igual. Esto se debe principalmente a dos aspectos.

(1) La concepción de la analogía del dominio, que se funda en supuestos ontológicos y teológicos y que exigen que un dominio solamente se genere en la relación jerárquica de los correlatos del dominio. Desde el punto de vista ontológico, no existe esta jerarquía entre los seres humanos y, por tanto, no debería existir un dominio propiamente dicho de uno sobre otro.

(2) Además, las estrategias para legitimar la esclavitud legal parecen ser deficientes, sobre todo si se enfoca la guerra justa como razón legitimadora de la esclavitud legal. Con todo, el derecho de gentes y las premisas teológicas y ontológicas (libertad, dominio) parecen excluirse mutuamente.

Soto es sin duda un pensador profundamente arraigado en la teología y filosofia de su tiempo y de su entorno. Por eso es poco probable que su obra, por aguda y sagaz que hubiese sido, se deba considerar como una obra moderna de Filosofía Política. Asumiendo el supuesto de una libertad intrínseca de todo ser humano se genera, a mi manera de ver, una incompatibilidad conceptual de 'dominio', entendido como un derecho subjetivo, y de 'esclavitud', entendida como la pérdida de libertad y como una consecuencia del estado del hombre después de la caída. No obstante, no es descabellado decir que el profundo análisis del dominio, presentado por Soto, haya asimismo forjado y condicionado a pensadores posteriores pertenecientes a la era moderna. ${ }^{42} \mathrm{Y}$ si bien la investigación ha avanzado considerablemente al respecto, todavía falta mucho camino por recorrer para llegar a una compresión acerca de la influencia de los pensadores de la Escuela de Salamanca sobre el desarrollo de la Filosofía Política Moderna. 